$\begin{array}{lllllllll}A & R & T & I & C & U & L & O\end{array}$

\title{
Una Teoría Retórica de la Sociedad*
}

\author{
Por: Javier Hernández García
}

\section{RESUMEN}

e plantea en este artículo la tesis de que la estrategia discursiva de Miguel Antonio Caro de integrar en una misma dinámica constituyente de la 1 civilización a la Lengua y al ordenamiento social (como Autoridad), rinde jugosos frutos conceptuales. Al hacer posible la postulación de una correspondencia sustantiva entre una "gramática de la lengua" y una "gramática de la sociedad" (entendida como civilización), y partiendo de la elaboración de postulados histórico sociales entresacados de las ciencias del lenguaje de la época, por los que se establecen, entre otras cosas, diferencias sustantivas entre lenguas complejamente desarrolladas y lenguas de menor complejidad, se extrapola un modelo de jerarquización de las sociedades humanas y de los hombres que las hablan y desarrollan que naturaliza, retorizándolas, las gradaciones, contraposiciones, junturas y distanciamientos constitutivos de la vida social. Teniendo en cuenta que para Caro el lenguaje es el primero y necesario elemento de sociabilidad, éste se autoconstituye en el mismo juego de vectores que se entrecruzan y combinan, avanzan y retroceden configurando la sociedad-civilización en la que el lenguaje se despliega y encarna, en un compartido camino que integra tradición y progreso, superioridad e inferioridad, hegemonía y subordinación.

* Este artículo contiene una síntesis de algunos temas desarrollados en la investigación en marcha, "La bandera de la Patria es Santa: E1 Pensamiento Tradicionista de Miguel Antonio Caro".

${ }^{1}$ Que recoge el texto de una conferencia leída poco antes en la A c a d e m i a Colombiana de la Lengua en Bogotá.

${ }^{2}$ OB3-uso, p. 43.

${ }^{3}$ OB3-uso, pp. 4344.

\section{Del Uso y de las Academias: Autoridad y Lengua}

En un artículo publicado en El Repertorio Colombiano, en enero de 1881, Del uso en sus relaciones con el lenguaje, ${ }^{1}$ Miguel Antonio Caro establecía relaciones entre los hechos, el uso y las normas en sociedad. Precisaba que el hecho merecía respeto y acatamiento, no por lo que era en sí, sino por lo que representaba; y que si el uso no era más que un hecho, se habría de seguir, por necesidad, que no se le acataría con el entendimiento. Es que los hechos, normalizados en los usos, continuaba afirmando, no deben aceptarse despóticos ni absolutos. Los hechos del uso deben ser sometidos, en cambio, a la razón de la ciencia y de la autoridad. ${ }^{2}$ El hecho cuando no tiene, ni admite, ni consiente fundamento alguno, alegado como razón única, es un insulto a la razón verdadera. "Para que el hecho lleve mis obsequios racionales, yo le exijo que en lo sustancial, aunque no en los pormenores, se apoye en una ley preexistente, o con ella se enlace de algún modo, 
aunque yo no la penetre en sus causas finales". ${ }^{4}$ Soberbia y locura es pedir las razones últimas de las cosas, pero sí es fuero de seres racionales exigir a los hechos que presenten su título como manifestaciones o como agentes de fuerzas superiores. Y es que no hay que remontarse a hipótesis imaginarias, como la del "átomo"; no hay que contentarse con "palabras provisionales o vacías" como la de "causalidad". En cambio, "leyes solicito -pedía-, cualesquiera que sean, porque legalidad es forma de justicia y realización del derecho; y cuanto más antigua la ley que descubro, más me satisface, porque por su antigüedad miro la alteza de su origen y lo benéfico de su institución. Ley es que en la vida de la sociedad estructura el orden de la "legalidad justa"; en el orden de las ideas, configura el reino luminoso de la racionalidad, y en el plano sobrenatural, configura el insondable ordenamiento providencial. Por ello, el conocimiento que los hechos del uso me conducen a sus leyes últimas, y puede describirse como el tránsito de lo casual a lo providencial, como ascensión de lo que es a lo que debe ser, del caso al Orden, "que es calor y es luz", lugar donde "el corazón naturalmente se regocija, sosiega y descansa el entendimiento". ${ }^{5}$

En la extensísima conferencia que comentamos el tema central giró en torno a las relaciones que se dan entre el uso popular de la lengua, por un lado, y, por el otro, el propio de las ciencias del lenguaje, de la erudición humanística, del saber magisterial, de la literatura, uso culto puesto en escena por parte de las instancias y actores autorizados de la lengua (academias, sociedades literarias y científicas, gramáticos, poetas, letrados, jurisconsultos, teólogos, tribunos). Estas relaciones explícitas se corresponden con otras más profundas, como aquellas establecidas entre los sistemas normativos (constituyentes del orden moral y político) y los hechos y los usos agenciados por los hombres que, diferencialmente, participan del desenvolvimiento de las civilizaciones en las que esos sistemas, por y en el lenguaje, se particularizan. Estas correspondencias refieren, a su vez, otro sistema vinculante. Es el que existe entre la gradación jerarquizada de autoridad moral y política de los diferentes agentes sociales en sus ámbitos de desempeño, por una parte, y la correspondiente a los diversos grado de autoridad que al uso del lenguaje se les reconoce a esos distintos agentes concurrentes, por la otra; reproduciéndose en este plano las gradaciones y diferencias que, elevando la erudición, ciencia y solvencia comunicativa de los cultores de la lengua por sobre el uso ingenuo y meramente práctico que de ésta hace el vulgo, cualifica y grada la autoridad y representatividad moral y política de los hablantes que con ella se expresan y por ella desarrollan su comercio de ideas y de cosas.

${ }^{4}$ OB3-uso, p 44.

${ }^{5}$ OB3-uso, p. 44. 


\section{- Correspondencias entre la República Política y la República de las} Letras

En el orden moral y en el orden legal, definidos por Caro como "círculos concéntricos", no es potestativo de los que gobiernan la sociedad demoler lo existente, a guisa de revolucionarios, ni reformar el mundo con fórmulas ideales, y en virtud de brevísimas síntesis filosóficas, a manera de ideólogos, desentendiéndose en un todo de aquello que el tiempo y el general consentimiento tienen sancionado. Pero en el extremo opuesto, no ha de mirar con indiferencia el moralista, ni el legislador aprobar indistintamente todo lo que se halle establecido. Es que "el arte de gobernar, y en términos generales, toda ciencia aplicada a la mejora de la sociedad o del individuo, la educación, en fin, es una suave violencia que la razón hace a la naturaleza [negrillas JHG]". ${ }^{6}$ Tratándose de círculos concéntricos, de manera correspondiente a lo que sucede en la sociedad de los hombres, lo mismo sucede, entonces, en la república literaria, "en la esfera del arte de hablar y de la crítica gramatical." Como los dirigentes y sabios en la sociedad de los hombres, los gramáticos y los escritores "no rompen en lucha abierta con el uso, y aun se ven obligados a contemporizar con muchas de sus exigencias; más todavía ejercen sobre él indisputable autoridad, lo dirigen, lo depuran, acaudalando y embelleciendo la lengua". ${ }^{7}$

\section{- La “Cuestión Principal": ¿Cuál es la Norma del Buen Decir?}

${ }^{6}$ OB3-uso, pp. 34-35. Caro concibe al "arte de gobernar" como una "ciencia aplicada" a la mejora de la sociedad. En varios lugares de su obra considera a la política como una "ciencia", y en particular dentro de las argumentaciones que desarrolla en defensa del aporte que la "ciencia española" ha hecho a la ciencia universal. Ver textos de Caro compilados por Antonio Curcio Altamar, en Ideario Hispánico, Instituto Colombiano de Cultura Hispánica, Bogotá, 1952,

${ }^{7}$ OB3-uso, p. 35.

${ }^{8}$ OB3-conf, p. 1158

${ }^{9}$ OB3- conf, p. 1159.
Uno de los principios vertebrales del pensamiento de Caro es el que postula que tanto en metafísica como en cuestión de moral y política, la Unidad es la expresión más patente de la Verdad, y que esa Verdad es fuente de todo Bien, motivo y meta de todo humano actuar. En el ámbito de la lengua, de manera correspondiente, es también la Unidad nota esencial de la Verdad, y medio de superar las zozobras de la diversidad a que está sujeta toda humana institución.

En ese entendido, para procurar la deseable unidad de la lengua -la institución humana más significativa- es necesario seguir una norma que la instaure y preserve, y sirva de ordenamiento regulador que impida que se desvíe de su "tipo primordial". ${ }^{8}$ Entroncadas esencialmente lengua y civilización humana, el ajuste a la Verdad-Una de la lengua es, al tiempo, su ajuste al Bien y a la Belleza; por lo que, en relación con la inervación de la lengua en la constitución de la civilización, "los medios para mantener la unidad de ella están relacionados por una parte con las ciencias morales y políticas y por otra parte con la estética: de un lado es una cuestión de derecho y de otro lado es una cuestión de buen gusto". 9 
Así, los principios que aplican a las ciencias y el desarrollo histórico concreto de la moral y la política se corresponden con los de la estética (de la expresión lingüística); los principios jurídicos y morales y los estéticos son paralelos y emanan de la misma fuente. Refiriéndose a la contradicción teórica y práctica en que caen muchas personas de su época, sobre todo los liberales utilitaristas colombianos, reclama que "los que creen que no existe más derecho que la fuerza o que no existe mas ley que la voluntad del mayor número", para no incurrir en flagrante contradicción, deberían "profesar en la estética el principio de que no existe más regla en materia del buen gusto, que el gusto de la mayoría, y en materia del buen decir que no existe otra regla que el uso de la mayoría". ${ }^{10}$ Sin embargo, ello no es así, puesto que en este campo, paradójicamente, defienden con celo el papel magisterial del saber de doctos y cultivados.

La teoría de que la voluntad del mayor número es la que determina el derecho, que ha sido la terca posición de ese utilitarismo colombiano desde los inicios de su vida republicana, "va derechamente a la teoría de que la fuerza es el derecho, y no hay medio de evitarlo, porque la mayoría puede creer una cosa o puede creer otra cosa opuesta". ${ }^{11}$ Haciendo una revisión histórica a las escuelas estéticas europeas, centradas en la cuestión fundamental de las relaciones entre el uso y la norma, entre el hecho y la razón, encuentra que se han venido a constituir posiciones encontradas, irreconciliables, que se han aglutinado en dos grandes escuelas "disidentes", tanto en materia de ciencias morales y políticas como en estética y filología: la que él llama escuela histórica, por una parte, y la denominada escuela filosófica, por la otra. ${ }^{12}$ La escuela histórica postula, según Caro, que todo lo que existe ha tenido derecho de existir y que ha sido bueno, esta es "la escuela de los hechos consumados, y viene a no reconocer otro dios que el éxito". ${ }^{13}$ La filosófica, en la otra orilla, establece que nada de lo existente se ajusta al modelo ideal, por tanto todo debe ser invalidado y reemplazado según un patrón que no se logra instaurar en el mundo humano.

Entre estos antagónicos extremos, en una razonada posición de equilibrio, se ha venido desarrollando, en la historia de la Civilización la Escuela de la Verdad, que viene a ser la Escuela Cristiana. Esta Escuela, asegura Caro, establece que lo que existe tiene derecho al respeto en cierto modo, incluso, los hechos calamitosos, los que pueden explicarse en lo político y social de la misma manera que en el orden físico: como un medio para perfeccionar lo existente, como "medios providenciales de corrección". ${ }^{14}$ Propone, según lo anterior, que se debe conciliar la historia (la progresión de los hechos en el tiempo y el espacio) y la filosofía (la progresión del pensamiento humano en esa historia); la escuela filosófica deberá plantear la modificación de lo existente, pero sin destruirlo; y, por su parte, la
${ }^{10}$ OB3- conf, p. 1159.

${ }^{11}$ OB3- conf, p. 1159.

12 OB3- conf, Caro en este mismo texto termina por solapar el término "escuela histórica" con el término "historia" como ciencia, y la "escuela filosófica" con la "filosofía" (actividad intelectual).

${ }^{13}$ OB3- conf, p. 1160.

${ }^{14}$ OB3 - conf, p. 1161. Esta es una escuela que, además de todas sus ventajas, por su visión positiva del discurrir del hombre en el siglo, "consuela." 
${ }^{15}$ OB3- conf, p. 1161.

${ }^{16}$ OB3-uso, pp. 76-77.

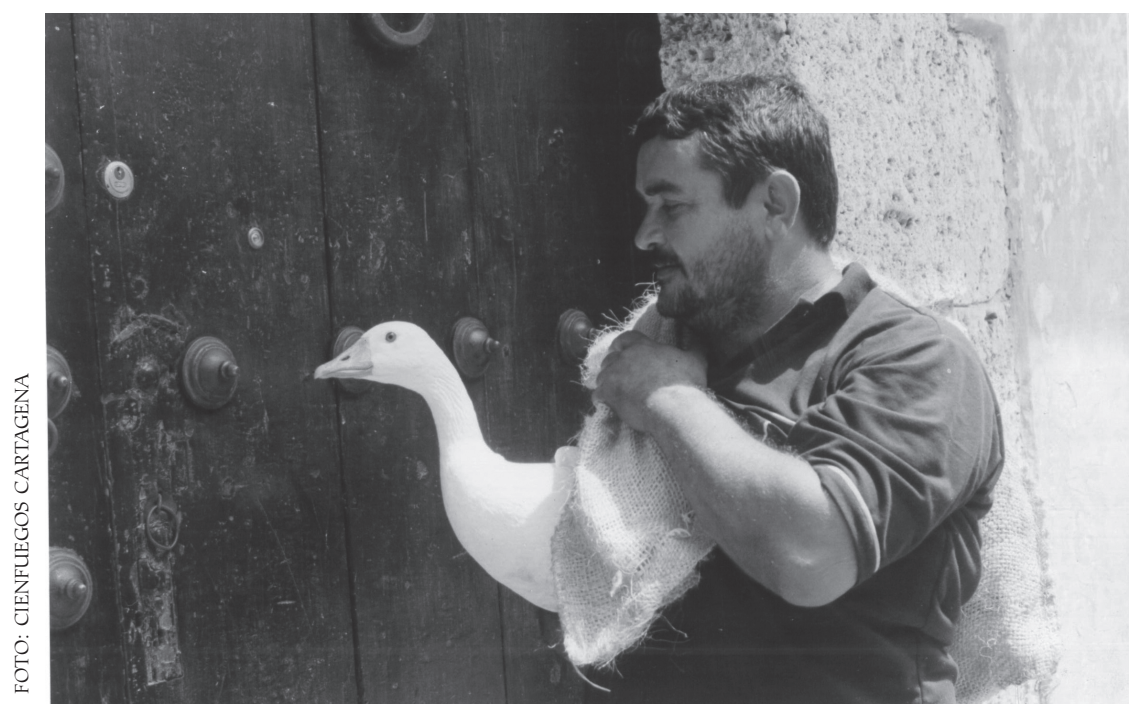

escuela histórica deberá aceptar lo existente, "pero no desechar las reformas que tienden a perfeccionar según leyes orgánicas su desenvolvimiento". ${ }^{15}$

A partir de esa contextualización general de las relaciones entre los usos -la historia- y las construcciones racionales humana -la filosofía-, Caro confirma su propia posición (que es, por supuesto, la de la Escuela cristiana) en relación con el uso y las ciencias en el campo específico del lenguaje. Afirma que el uso no es ni dueño ni único guía del lenguaje: "la experiencia enseña que el uso [del lenguaje] es susceptible de educación y perfeccionamiento; sino que debe el lenguaje desplegarse dentro de los cánones de la normatividad racional que fundamenta y encauza su desarrollo histórico; normatividad y encauzamiento que está en manos del magisterio educador de los escritores clásicos (literarios y científicos), que ennoblecieron y ornamentaron la lengua. En este entendido, entonces, las ciencias de la gramática y de la lógica, así como la erudición y la crítica se encargan de depurar, regularizar y acicalar la lengua; y las Academias, comunidad y espacio institucional de ese quehacer científico, crítico y depurador, son las instancias autorizadas responsables de conciliar lo razonable y lo conveniente, el interés de la ciencia con los de la nación, ejercen una autoridad benéfica, un verdadero magisterio retórico, una auténtica hegemonía magisterial en el campo de la lengua. ${ }^{16}$

De tal manera, tanto en la República Literaria como en la República Política se hacen necesarios, entonces, los agentes individuales y los cuerpos organizados que rijan y orienten los usos de los asociados. La lengua se desarrolla y conserva mejor no porque simplemente se aglomeren individuos que la hablen de una manera o de otra -así como no se forma una sociedad como un simple cuerpo orgánico por la mera yuxtaposición de los individuos; es menester que se constituyan "sociedades literarias", que representen dos elementos, como ocurre en las monarquías constitucionales: por un lado, que representen el uso de las mayorías $y$, juntamente, que representen el uso de los grandes escritores, procurando conservar el gusto entre unos y otros; es decir, que, en el mismo movimiento, "representen la tradición, que representen el progreso. Deben ser cuerpos a un 
mismo tiempo oligárquicos y democráticos, porque si no hay un cuerpo no hay una sociedad que sirva para establecer estos principios; los dos elementos se encontrarían en constante pugna y no adelantaría nada el progreso de la lengua". Son estas sociedades literarias, centros desde donde se irradia el poder docente, las que producen estos bienes para la lengua, neológica y conservadora a la vez. ${ }^{17}$

\section{Papel Magisterial de los Literatos y Cultores de la Lengua}

Así, en resumidas cuentas, la fuente de la innovación, de su progreso, no está en el uso que le dan las mayorías a la lengua, como se supone con demasiada frecuencia, sino en el que proviene de sus creadores, sus poetas y escritores, verdaderos cultivadores -cultores- de la lengua. Afirma Caro que tenemos una hermosa, rica y fértil lengua, y nos aprovechamos hoy de sus inagotables recursos, sin acordarnos de que la fuerza y la savia de su organismo "es la vida de sus escritores ilustres, de los clásicos españoles; aportes del genio que con el tiempo se presentan con el vago nombre de uso, que sirve, como el de casualidad "a encubrir y postergar el mérito personal del genio creador". ${ }^{18}$

\section{Las Ciencias del Lenguaje}

\section{- La Gramática. Definición, Objeto y Propósito}

Para Caro, la ciencia de la gramática se constituye en la exposición ordenada y reflexiva del mecanismo de una lengua; según éste, es el "conjunto de reglas generales sobre sus diversos recursos y modos de expresión, fundadas en el uso de la sociedad culta y de los escritores atildados; enseña a hablar y a escribir con corrección y propiedad". ${ }^{19}$ Introduce Caro en esta definición varias precisiones y distinciones importantes. Por una parte, el objeto de la gramática es el "mecanismo de una lengua", patrones relacionales abordados por esta disciplina tanto en un sentido descriptivo como, en especial, en un sentido normativo, en la medida en que configura un "conjunto de reglas generales sobre sus diversos recursos y modos de expresión". Por su parte, la materia empírica de la indagación científica gramatical está dada por "el uso de la sociedad culta y de los escritores atildados". Incluye, por último, un propósito pedagógico esencial, en la medida en que es la gramática la que enseña a "hablar y escribir con corrección y propiedad", corrección y propiedad que corresponde a la del uso de la sociedad culta y de los escritores atildados.

\footnotetext{
${ }^{17}$ OB3- conf, p. 1174

18 OB3-uso, p. 61.

${ }^{19}$ OB2-int, p. 16.
} 
${ }^{20}$ DEF, p. 39.

${ }^{21}$ OB2-int, p. 17

${ }^{22}$ OB2-int, p. 17.

${ }^{23}$ DEF, p. 39. contrastación analítica de los usos cotidianos e históricos del habla -que constituyen el universo práctico de desenvolvimiento de la lengua- con los principios racionales formalizados en el ámbito de la gramática, materializados de manera ejemplar en el uso autorizado de los cultores de la lengua. Por supuesto, además, que el lenguaje, como actividad humana eminente, no podía quedar fuera de rigor formal y la elegancia expresiva de las buenas costumbres, sujeto susceptible, como el que más, de educación y perfeccionamiento. ${ }^{20}$

Así, en cuanto examina las relaciones entre las palabras y las ideas, se da la mano con la lógica e "ideología"; y en cuanto fija las leyes del idioma, la indagación lingüística va ligada con las investigaciones filológicas. ${ }^{21}$ En ese sentido, Caro pretende conseguir, en sus propias palabras, una articulación equilibrada entre lo filosófico y lo científico, y entre éstos y los usos prácticos del lenguaje, matriz de la espontaneidad y gracia en el decir oral y escrito, conectadas con la frescura y encantos de la vida, pero liberando a éste uso de los resabios de la rutina. En este punto, Caro introduce el papel del uso cotidiano, no ilustrado, de la lengua, en los desarrollos teóricos, normativos y descriptivos de la gramática. Esta compleja composición y propósito de la gramática de la lengua, que incluye aportes y desarrollos extracientíficos, como son los usos populares, le hace reconocer que el método gramatical "podría ser mejor"; pero en éstos casos, como en general en materia de clasificaciones, "no es mejor lo más exacto, sino lo más claro y lo más útil". 22 En fin, el balanceo de Caro entre gramática como conjunto de reglas intrínsecas a la lengua misma (mecanismo formal) y gramática como conjunto de reglas extrínsecas impuestas por una autoridad exterior (entendida entonces como corrección) explica y particulariza sus trabajos en el campo de estudio de la lengua castellana. Esta perspectiva, al mismo tiempo académica y normativa, se articula muy bien con los propósitos magisteriales de toda su obra. ${ }^{23}$

\section{- La Lengua y las Leyes}

"Un observador ignorante no descubrirá leyes morales sino variedad contradictoria y monstruosa en las costumbres de los diferentes pueblos, ni justicia, sino locos caprichos o intereses personales en la legislación de las diferentes épocas y naciones. Pero el verdadero jurisperito confronta la equidad con la justicia; rastrea la ley natural y estudia la ley escrita; ora se funda en antecedentes establecidos, ya se eleva a consideraciones de filosofía social; armoniza, en fin, el hecho con el derecho, y de ahí la jurisprudencia. La gramática es una especie de jurisprudencia [JHG]. El buen gramático es hombre doctísimo y sagaz: toma como base de su ciencia el uso, pero cuando el uso es vario o equívoco, decide conforme lo dicta la etimología, o según las leyes de la analogía y de la gramática 
comparada, o a la luz de la filosofía del lenguaje y de la lógica. Unas veces prescribe lo que está sancionado, otras, si el punto es controvertible, propone y aconseja lo más conveniente. Y así como en lo moral y jurídico, consultamos con confianza a los expositores de nota que resumen, clasifican e ilustran los principios de la ciencia, no consignados en códigos determinados, del propio modo los gramáticos como Bello y Cuervo, son a manera de exploradores que ahorrándonos en muchos casos el trabajo que ellos se tomaron, nos guían en el complicado arte de la lengua con sabias y sólidas enseñanzas." 24

\section{- Filología: Historia de las Palabras, Historia de la Civilización}

Para Caro, "la historia de las palabras es fidelísimo reflejo de la historia, de las costumbres, de la ciencia, de la filosofía, de la poesía, de la civilización, en suma". ${ }^{25}$ Por tanto, "por las evidencias del lenguaje", y gracias a los estudios filológicos de las etimologías, dice, se hace posible descubrir "los rasgos característicos de la cultura" de un pueblo. Es que la etimología de una palabra es la parte sustantiva, radical, de los vocablos, aquello que subsiste en medio de los cambios de la corriente de la pronunciación, aquello que lo sustenta-uno en los distintos tiempos y épocas, y retarda su desaparición. ${ }^{26}$

Porque las palabras ascienden, descienden y se desvían de su significación original, a virtud de las mudanzas que experimenta el estado social, político y religioso de los pueblos, así como por medio de giros mentales y de naturales asociaciones de ideas que llamamos metáforas" ${ }^{27}$ En este sentido, la etimología, encierra en sí la historia de la lengua y de la relaciones de la lengua con la civilización de la cual es matriz y resultante al mismo tiempo. ${ }^{28}$ En consonancia con esto, frente, y por debajo -en el universal sistema dicotómico de valores de Caro- del hombre científico y del sabio está el vulgo, que no tiene sino una inteligencia vaga, una aprensión confusa y aproximativa del valor del lenguaje. Es el lenguaje, pues, ciencia fósil y muda para quien lo habla como mero signo de comunicación, pero no es letra muerta para el que lo escudriña y lo medita". ${ }^{29}$

\section{- Lexicología y Lexicografía. Diccionario, Civilización Humana y Providencia}

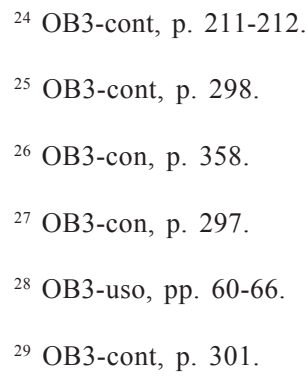

${ }^{26}$ OB3-con, p. 358.

${ }^{27}$ OB3-con, p. 297.

${ }^{28}$ OB3-uso, pp. 60-66.

${ }^{29}$ OB3-cont, p. 301. Caro constataciones empíricas y científicas de su posición. Al tiempo que el desarrollo histórico de las lenguas muestra su esencial inserción en el mundo social, político, moral y cultural de los pueblos que se expresan con ella, es decir, a la par que las lenguas son instituciones históricas, también "las lenguas vivas 
${ }^{30}$ OB3-par, p. 660.

${ }^{31}$ OB3-par, p. 659.

${ }^{32}$ Citado por DEF, p. 88.

${ }^{33}$ Y lo más crítico para Caro es que esta barrera la tropezaron los modernos $y$ c on t e m p or án e os enemigos del cristianismo que lo combaten en el orden intelectual. Lo hacen forzando el sentido de las palabras, despojándolas de sus sentidos espirituales. Destutt de Tracy elimina el sentido espiritual del verbo pensar; Jeremy Bentham el del sustantivo virtud; otros, lo hacen con términos como "pensamiento", "hombre", "amor". "A esta irrupción de los bárbaros de la ciencia es preciso oponer la sanción por los siglos de las acepciones espirituales de las voces consagradas solemnemente en los Diccionarios. Y si todas las lenguas modernas están cristianizadas, ninguna abunda tanto en sentido espiritual como la castellana cuya principal riqueza se registra juntamente que en su teatro, eminentemente espiritual, en sus libros religiosos." OB3-dic, p. 701.

${ }^{34}$ OB3-cont, p. 359.

${ }^{35}$ OB3-cont, p. 359. son organismos que se desenvuelven y crecen conforme a las leyes naturales", poseen, por tanto, una estructura "natural" cuyo desarrollo atiende tanto a los patrones de su propia "naturaleza" ontológica y moral, como a los del desarrollo de las sociedades. ${ }^{30}$ En ese entendido, así como la filología y los estudios histórico etimológicos de la lengua nos permitían acceder a la evolución en el tiempo de ese "organismo", al tiempo natural y social que es la lengua, la lexicografía y la lexicología se constituyen en inventarios razonados de esa inacabada progresión de la lengua en el tiempo y el espacio históricos. ${ }^{31}$

En consecuencia, y para resolver la humana dicotomía entre el cambio y la estabilidad, la naturaleza y la historia, la diversidad y la unidad, en referencia al lenguaje, Caro introduce la solución metafísica de la que ha echado mano en otros contextos de su discurso. Dice que el desarrollo histórico de las lenguas llevará necesariamente a la proliferación de diccionarios -de neologismos, arcaísmos, voces populares, voces técnicas, provincialismos, de apellidos, nombres geográficos, etc.- por lo que ninguno será jamás completo; y que esa progresión no es infinita, en la medida en que pertenece al Plan providencial dentro del cual se incluye, por supuesto, la Palabra y su desenvolvimiento en el mundo. Esta interminada progresión de la lengua forma parte de un Plan, tiene un sentido, y una especie de entorno metafísico: la "mente de Dios". Como él lo afirma, "el único diccionario completo está en la mente de Dios y no en las limitadas facultades humanas". ${ }^{32}$ Por ende, es inmensa la responsabilidad magisterial que Caro otorga al filólogo, lexicógrafo y lexicólogo, al gramático en general, en sus tareas científicas con la lengua. Tareas que se constituyen en una auscultación, en última instancia, de la Providencia, del Plan Divino, de la Mente de Dios. ${ }^{33}$ El investigador y cultor de la lengua humana, termina por encontrarse con el místico hermeneuta de la Palabra Divina.

\section{- Oralidad y Escritura. Continuidad y Cambio: Ortografía y Fonética}

"El habla y la escritura son dos corrientes paralelas; la primera camina de suyo con mal avisada rapidez; la segunda modera sus ímpetus. La escritura es el vínculo salvador entre el escritor antiguo y el moderno; entre el que vive aquende el mar y el ultramarino; en una palabra, es la lengua uniforme en el tiempo y el espacio, la unidad en la variedad". ${ }^{34}$ Frente a ellas, y por debajo de ellas, en cambio, las lenguas habladas desaparecen más presto que las escritas, carentes de ese vínculo salvador, de esa uniformidad integradora. "Por eso los idiomas modernos europeos prometen eternizarse, merced a la imprenta" 35 y los lenguajes predominantemente orales, no europeos, están condenados a su desaparición y descomposición irremediable. 


\section{$>$ El Saber de la Lengua Institucionalizado en la República Política}

Más atrás habíamos destacado la posición de Caro en relación con la diferencia entre el saber-hablar cotidiano, de sentido común, y el saber-hablar culto, producto de una formación científica y literaria. En el ejercicio escritural Caro establece una distinción similar. Saber leer y escribir, afirma Caro, es base de toda educación intelectual, y es condición que señalan las leyes para que un colombiano pueda ejercer el primero y fundamental de los derechos políticos, el derecho de votar. Sin embargo, la ley no establece la diferencia -no puede hacerloentre deletrear y leer, entre hacer letras y escribir. Raros son los que leen bien, como son pocos los que redactan bien. ${ }^{36}$ Deletrear $y$ firmar son operaciones mecánicas, son ejercicio, y no arte, son cuerpo sin alma. Saber leer y escribir, en "el sentido artístico y más elevado de las palabras" es tanto don de la naturaleza como fruto del estudio, grado de perfección que pocos alcanzan. Esta distinción no pueden hacerla los legisladores, pero sí corresponde hacerlas a las universidades, a las escuelas normales, a la Dirección de Instrucción Pública, "en una palabra, el Poder Docente" ${ }^{37}$

Extendiendo el anterior argumento, nos permitimos imputar a Caro un principio vertebrador de su pensamiento político: Saber leer y escribir, fundado en un conocimiento científico de la lengua, un uso moderado por la corrección, eficacia y elegancia en la expresión, es condición y al tiempo expresión, del ejercicio del poder político. La categoría de Poder Docente a la que se refería Caro, aludiendo de manera particular al sistema institucional que se encarga de la enseñanza del uso correcto y la comprensión cabal del idioma nacional, la podemos hacer extensiva a todos los sistemas y procesos institucionalizados, incluyendo sus actores e interacciones, por los cuales se cumple la socialización, función de la tradición y la innovación, del lenguaje. ${ }^{38}$

\section{Los Ciudadanos y los Espacios de la Nación Gramatical. Una Retórica de la Nación como "Theatrum Mundi" 39}

Hemos visto como Caro considera las lenguas históricas como un producto colectivo al tiempo tradicional y parcialmente cambiante, desplegadas como frutos de la acción secular de dos "artífices" principales, con funciones, aportes y valoraciones diferenciadas dentro del proceso: el pueblo y los doctos: "Toda lengua es una corriente tradicional, cuyos orígenes primeros se pierden en la oscuridad de los tiempos. Sus instintos son históricos." En contra de lo dicho por filósofos del lenguaje como Condillac y Tracy y "demás filosofastros del siglo XVIII", no es posible "hacer pueblos con constituciones ni lenguas con
${ }^{36}$ OB3-eloc, p. 429.

${ }^{37}$ OB3-eloc, p. 430. Cfr. En ese mismo texto, la propuesta de MAC de organizar, dentro de este "magisterio retórico", los Talleres de buenos lectores y de maestros del bien leer" (organización de las artes $o$ ciencias del bien leer).

${ }^{38}$ El poder docente 10 constituyen las instancias de poder "educacionales", diferenciadas por Caro, del poder político propiamente dicho, pero íntimamente vinculados el uno con el otro puesto que ese poder docente debe ser controlado, orientado, signado, por el poder político, rostro mundano del poder moral del auténtico Magisterio civilizatorio en la nación. Esta concepción de los vínculos sustantivos entre el Saber y el Poder no era exclusiva de Caro. Otro autor c o 1 o m b i a $n$ o c on t e m p or á n e o, moderado tradicionalista, afirmaba al respecto: "El naturalista, el químico, el ingeniero estudian para dominar la naturaleza, el sacerdote y el letrado estudian para dominar los pueblos." Miguel Samper, Escritos Políticos y Económicos, Banco de la República, 1977, Tomo I, pp. 26-27, citado por Guerrero Gerardo, "Universidad Pública: Modernización y Modernidad 1826-1880, en Revista Historia de la Educación Colombiana, Universidad Pedagógica y Tecnológica de Colombia, Año I, $\mathrm{N}^{\circ} 1$, Octubre 1998, p. 109.

39 Empleamos aquí el término theatrum no en el sentido restringido virgiliano de "lugar destinado para juegos o diversiones públicas" o de "pieza de teatro", sino en 
el sentido metafórico más amplio y general (Quintiliano, Horacio, Cicerón) de concurso de espectadores, o de oyentes, de junta, auditorio; así como de lugar en donde se está a la vista de todo el mundo, de escenario en general. Cfr. Valbuena, Diccionario LatinoEspañol EspañolLatino, Librería de la Vda. de Ch. Bouret, París, s.f. p. 562

${ }^{40}$ OB3-par, pp. 661-662.

${ }^{41}$ OB3-par, pp. 661-662. gramática. Nadie es autor ni dueño absoluto de una lengua. Pero el pueblo y los doctos son artífices de la lengua, en cuanto la ponen en movimiento, y la manejan enriqueciéndola o transformándola". ${ }^{40}$

Pero en esta imputación de responsabilidades, en la República de las Letras —así como ocurre en la República Política - hay una adjudicación diferenciada jerárquicamente de funciones, tareas, derechos y responsabilidades entre, por una parte, los cultores y doctos (sabios y poetas) y, por otra, el "pueblo". Establece Caro que corresponde al pueblo nominar "vulgarmente" a las cosas; al sabio, darles el nombre científico, y al artista producir, con nuevas combinaciones, su "ennoblecimiento". En punto a vocabulario, el pueblo da el nombre vulgar de cosas poco conocidas que no tenían nombre literario. El sabio especialista les da el nombre científico, y debe dárselo acomodado a la índole del idioma. El prosador ingenioso, el poeta mágico, adopta, hermosea por medio de felices combinaciones sintácticas..., ennoblece, graba en la memoria e inmortaliza el nombre vulgar, a veces el científico". ${ }^{41}$

\section{- Espacios Sociales y Actores de la Hegemonía según la Oratoria (Elocuencia) Magisterial}

Tal vez uno de las perspectivas de análisis que permite acceder a los niveles más cruciales del "sistema de pensamiento" de Caro, es aquel que nos permite adentrarnos en ese espacio discursivo donde se configura la sustantiva articulación de los planos religioso, metafísico, lógico, lingüístico, político y sociohistórico que constituye lo más esencial de sus postulados. Y, más específicamente formulado, una de las tesis preeminentes expresivas de dicha articulación es aquella en la que Caro establece una particular relación entre lenguaje, poder y representación. Consideramos que para Caro la representación, en cuanto ejercicio público del poder (postulado como autoridad de presentarse legítimamente a nombre de Otros y ante Otros) es un curso de acción que se despliega como acción pública autorizada por un Gramática (como ciencia) y una Elocuencia Retórica (su correcta expresión) que ordenan y significan esa Acción, y, al mismo tiempo, es el discurso mismo autorizado que esa acción pública representativa presenta ante los Otros autorizadamente, constituyendo en el proceso al ámbito de la comunicación pública en un Texto eminente: la República Política a la manera de una República de las Letras; en sus palabras, la Civilización humana, ese theatrum mundi en el que se despliega, según un dictum original, la Palabra providencial (que habrá de cumplir su trascendental designo al devenir, en el curso de los tiempos, Civilización Cristiana). 
De esta manera, nos atrevemos a pensar que en Caro el foro (en sentido baconiano) es el lugar de representación del poder como discurso, como lenguaje, y ámbito de representación de la lengua como poder. Por ello, pensamos, su reflexión sobre el lenguaje, fundamenta su teoría política. El orden de la gramática y la retórica, es la trama en la que se teje la urdimbre del orden de lo político. Y ambos órdenes, por supuesto, constitutivos del orden de la Palabra civilizatoria, transparentan, a aquellos que tienen ojos para ver y oídos para escuchar, el orden de la Palabra Divina, esa enunciada el último día de la Creación. Lo que hace que la reflexión sobre el poder y la cultura en Caro, termine, al final de cuentas, siendo un análisis del devenir insondable de la Providencia en el mundo, libreto místico de los avatares de la civilización humana y del poder que los ordena y da sentido como discurso. Un devenir, en últimas, inapelable.

En este entendido, entonces, el gran Texto que es la civilización humana está constituida por textos particulares, unos "mejor redactados" y mejor dichos que otros, cuyo desenvolvimiento en el tiempo y en el espacio van constituyendo el theatrum mundi en el que se representa nuestro papel según los tipos de parlamentos que se deban enunciar, escritos unos en lenguas portadoras de civilización, lenguas que llama "literarias y clásicas" y otros en lenguas que no alcanzaron a desarrollar todas las características de un lenguaje civilizado (esos

42 OB1-darw, p. 1090.

${ }^{43}$ El uso que aquí damos a la categoría de Poder Docente -empleada por Caro para referirse a las instancias institucionales que en el Estado se ocupan de la educación pública- amplía la significación específica que él le da, para hacerla extensible a un cierto modo de organización institucionalizada de las relaciones de poder que se dan entre el saber y el conjunto de las prácticas sociales en colectividades civilizadas. "idiomas iliterarios" o "lenguas bárbaras", esa suerte de "tronco rudo que no da flores"). ${ }^{42}$

\section{- Los Héroes y Antihéroes Culturales del Magisterio Retórico}

Ya arriba hemos hecho referencia a algunos de los miembros y papeles de los grandes héroes civilizatorios en el campo de la lengua, esos "escritores atildados" que conforman la "sociedad culta", esa verdadera protagonista y responsable de una Hegemonía Magisterial en las sociedades humanas, e institucionalizada en una especie de Poder Docente, cuya función rectora y educadora se cumple en el seno del "pueblo", agente colectivo cuyo papel creador en el campo de la lengua/civilización se reconoce, pero subsidiario y sujeto a la tutoría magisterial de las agentes de la sociedad culta. Es en el contexto de este magisterio retórico que -utilizando una expresión del mismo Caro- nominamos Poder Docente, ${ }^{43}$ que elabora

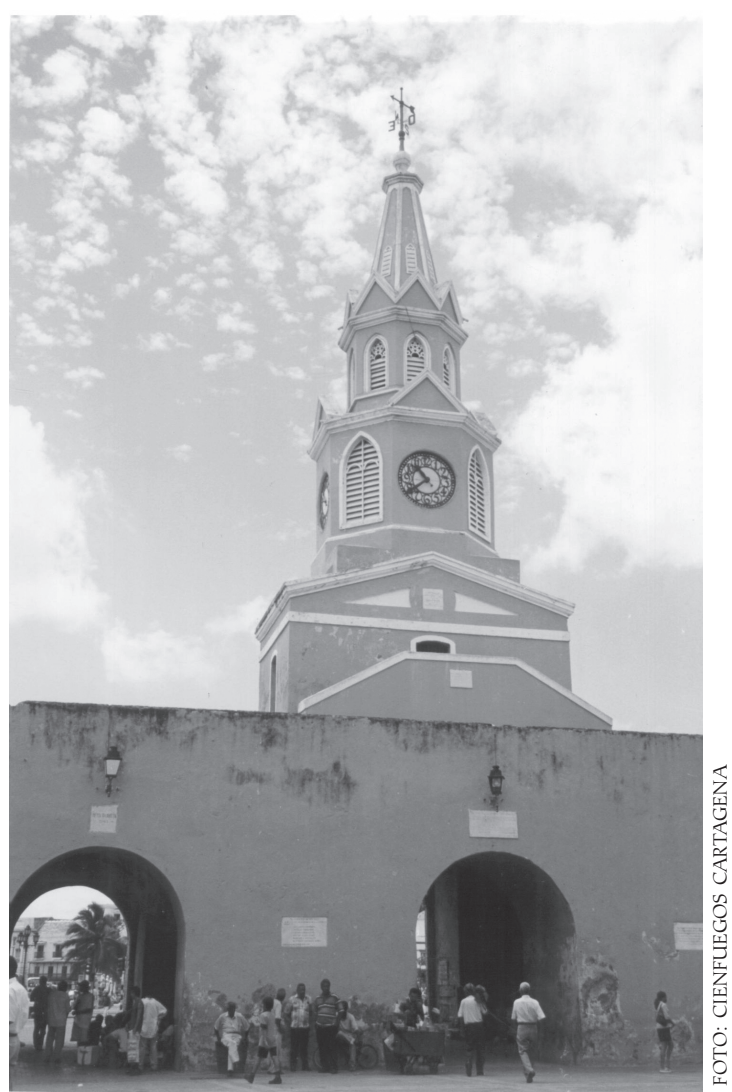


${ }^{44}$ OB3-uso, p. 44. En el texto comentado, la Galería incluye, junto con los grandes Héroes Civilizatorios nombrados, variantes, modalidades, subespecies. Por ejemplo, el tipo del Teólogo, acoge en su seno la figura del Misionero, una especial variedad de magistratura de Ley Divina, que junta en sí las funciones civilizatorias del Místico y del Filólogo/Científico, actor esencial en "tierras de infieles" de culturas iletradas y bárbaras, como fueron las americanas: el Misionero.

${ }^{45}$ Por tinterillo, en la terminología política colombiana de la época, particularmente la de Caro.

${ }^{46}$ OB3-par, pp. 641-642. "Gramaticastros son aquellos que "sin haber estudiado, ni pensado en estudiar las leyes del lenguaje, e incapaces de elevarse a los principios en que se fundan las reglas, erigen en dogma el precepto de cualquier doctor particular..." OB3par, p. 641. Caro postula aquí la necesidad de reflexionar sobre la critica al pseudocientismo del gramaticastro como punto de arranque para la crítica a toda posición inconsistente de tipo científico y político.

${ }^{47}$ Cfr. OB3-eloc, p. 438 y ss.

${ }^{48}$ En OB3-eloc. En algunos lugares de su obra, Caro podemos encontrar el reparto de la galería de Héroes civilizatorios a que aludimos arriba. Eran sus miembros más representativos aquellos que conforman la trilogía de Héroes fundadores. Son ellos el Jurisconsulto, magistrado de la Legalidad Justa, cuyo quehacer y lugar en la sociedad civilizada le hacen digno de "clamoroso acatamiento"; el Filósofo de la Ley Natural, Luz de la Civilización, magistrado cuyo sabio ejercicio se convierte en fuente de reconocimiento universal, y, por último, el Teólogo, místico y sapientísimo explorador del reino inefable de la Ley Providencial, cuya suprema exégesis y magisterio sacro lo hacen merecedor en la sociedad de acatamiento reverencial. ${ }^{44}$

\section{Los Antihéroes o Pseudo- Héroes Civilizatorios}

Por supuesto, frente a esta Galería civilizatoria se levantan numerosos enemigos de la obra misma de la civilización, que se esconden so capa de contradictores, en especies de asociaciones de pseudo-cientistas y pseudo-dirigentes, casi siempre liberales, enemigos domésticos de la libertad del bien y de la ciencia de la verdad; más dañinos que el enemigo declarado a la causa que desacreditan sirviéndola de mala manera. Todos éstos guardan, desde su perversa posición, una distancia esencial con los auténticos miembros del Poder Docente: "Son los gramaticastros al filólogo lo que el poetastro al poeta, lo que el criticastro al crítico, lo que el politicastro al estadista, lo que el sapista ${ }^{45}$ al jurisconsulto, lo que el teologizante de afición al teólogo, lo que el supersticioso al creyente, lo que la máscara al rostro humano, lo que lo contrahecho y apócrifo a lo natural y auténtico". ${ }^{46}$

\section{- Hablar Bien: Espacios y Actores de la Elocuente Oratoria}

La Oratoria, como la Elocuencia y la Declamación, se constituyen en el arte de hablar en público. ${ }^{47}$ La Oratoria que se ocupa de fijar los cánones de la correcta y efectiva (elocuente) expresión, se despliega socialmente en espacios, con actores y en formas discursivas particulares. El Hablante, que es un Orador domina con la palabra, y se ayuda del accionado y el gesto, de esta manera representa el discurso cuya racionalidad (verdad, sería la palabra de Caro) está garantizada, porque es su Autor, autoridad sustentada en la indagación, conceptualización y argumentación propia de su magisterial categoría de jurisconsulto, letrado, filólogo, filósofo, teólogo, educador, hombre de Letras, sesudo estadista, etc. ${ }^{48}$

Siguiendo las observaciones hechas por Caro en el texto que comentamos, el espacio público donde se despliega esta comunicación se particulariza en tres modalidades, la del espacio sagrado, la del espacio profano y la del espacio estético o artístico. Estos Actores/Agentes civilizadores, en el ámbito público 
institucionalizado del Hablar, clasificados -ordenados- según el tipo de escenario donde discurra su discurso y las formas del texto que acoja su comunicación magisterial, pueden ser repartidos así:

\section{$>$ En los Espacios Sagrados/Eclesiales:}

Oratoria / Elocuencia Sacra: Es la que establecen los cánones de expresión pública de los eclesiásticos:

- Actores/Agentes Civilizadores: los que en ella se ejercitan son los predicadores (prelados)

- Espacio Público o "Teatro" de Ejercicio: El Púlpito

- Formas Discursivas: Sermones, Homilías, etc.

\section{$>$ En los Espacios Profanos Político-civiles:}

Oratoria / Elocuencia Profana: Establecen los cánones de expresión pública en dos contextos expresivos:

- Político: Es la propia de las formas discursivas de los tribunos y dirigentes públicos.

Actores/Agentes civilizadores: los tribunos y políticos (estadistas, generalmente de profesión abogados)

Espacio Público o "Teatro" de Ejercicio: No institucionales: Plazas; Institucionales: congresos y asambleas, parlamentos.

Formas Discursivas: Las arengas de los tribunos (ante muchedumbres) y los discursos de los oradores (ante actores políticos institucionales).

- Forense: Es la que trata las reglas de oratoria de la defensa jurídica Actores/Agentes civilizadores: Abogados, jurisperitos, jurisconsultos. Espacio Público o "Teatro" de Ejercicio: Los tribunales y foros. Formas Discursivas: Alegatos.

\section{En Espacios Públicos Artísticos:}

Una tercera variante de las artes de la Declamación, que no se incluye entre los componentes de la Oratoria, es la que Caro llama propiamente "teatral", que se integra a las dos anteriores, sin embargo, por su carácter público.

Declamación Teatral: que comprende todos los medios de expresión de que se valen los actores en escena. Arte de representar, disponiendo de referencias, casi siempre indirectas y de pasada, a los integrantes de las Galerías populares del theatrum mundi de la Palabra. Por ejemplo, comentando las

"A p u n t a c i o n e s Críticas..." de Rufino Cuervo, dice que las correcciones al lenguaje bogotano elaboradas por ese ilustre hombre de ciencia iban dirigidas a quien pudiera o quisiera o debiera aprovecharse de ellas, pero que eso no quería decir, como le criticaron en su momento, que hubiesen sido hechas encaminadas a "albañiles y zapateros, lo mismo que a tahúres y gente de mala vida"; Obras, Tomo II, p. 191. Comentando la conveniencia de intensificar en Colombia el estudio y cumplimiento de la Prosodia, se refería a lo conveniente que habrá de ser para corregir las malas acentuaciones que se conservan entre "gente zafia y grosera."

Obras, Tomo II, p. 218 
todos los medios de expresión, de las palabras, del gesto y de la acción, incluso del disfraz, cualesquiera obras dramáticas. ${ }^{49}$

Actores/Agentes civilizadores: Artistas Teatrales. Espacio Público o "Teatro" de Ejercicio: Salas de Teatro. Formas Discursivas: Piezas Dramáticas, Textos Teatrales.

\section{- Espacios Privados y Actores del Magisterio Retórico desde la Elocución}

Tratándose de una lengua como la castellana, que se habla por diversos pueblos de un mismo origen, los cuales, sin embargo, no mantienen como debieran, estrechas relaciones, "el peligro de que el idioma se barbarice de mil modos en su forma oral", es mayor, y más urgente por lo mismo la obligación en que están los gobiernos ilustrados de fomentar el estudio de la elocución." 50 Esto es aún más urgente en algunas partes de América, y sobre todo en aquellas comarcas donde predominan las razas indígenas, donde la lengua castellana, "ensordeciéndose y debilitándose, se ha desviado de su tipo fónico". ${ }^{51}$

Es que la elocución "es la vida del lenguaje". Es la forma oral la propia de las lenguas vivas, y precisamente las alteraciones viciosas o dialécticas [en el sentido de dialectales JHG] de la pronunciación "son el camino por donde las lenguas degeneran, multiplicándose, fenómeno que hace crecer, dice Bello, los embarazos de la comunicación y comercio humano, medios tan poderosos de civilización y felicidad." 52 Por la elocución "se conservan las lenguas y se cultivan los hombres, porque la palabra y el pensamiento son inseparables y casi indiscernibles". ${ }^{53}$ "Sin elocución, adiós poesía, adiós oratoria". ${ }^{54}$

\section{$>$ Elocución: Ciencia y Arte}

La Elocución atañe al Magisterio Retórico, en el ámbito del discurso privado. Formas menores aunque igualmente representativas de la "cultura superior",

${ }^{49}$ OB3-eloc

${ }^{50}$ OB3-eloc, p. 439.

${ }^{51}$ OB3-eloc, p. 493.

52 OB3-eloc, pp. 438439.

${ }^{53}$ OB3-eloc, p. 440

${ }^{54}$ OB3-eloc,p. 440.

${ }^{55}$ OB3-eloc, p. 440 muy cercanas al "arte". Se define a la Elocución como "el arte de proferir los sonidos, las palabras y las cláusulas, cuando hablamos o leemos, con exactitud y propiedad, y con la expresión y modulación convenientes". ${ }^{55}$ La elocución, como tal, en cuanto trata no a la voz como instrumento, sino al lenguaje como signo, es un arte. Son dos las actividades que se inscriben en ese arte de la Elocución; por una parte, La Lectura, esa "elocuencia modesta" en la que el lector no tiene casi más instrumento que la palabra, pero bien articulada y convenientemente modulada; y la Recitación, intermediaria entre la lectura y la declamación. 


\section{Las Ventajas de no Hablar la Lengua Mosca}

Tomando en consideración lo comentado hasta aquí, es posible comprender por qué Caro desarrolla, ampliándola, matizándola, y, sobre todo, defendiéndola ardorosamente de sus detractores a lo largo de su larga carrera de estudioso, cultor y crítico de la lengua, la íntima correspondencia que existe entre la afirmación de que el lenguaje humano debe desenvolverse en el camino ascendente de las Civilizaciones sin viciar su índole original, es decir, sin quebrantar las leyes gramáticas (formas, tipos, casos y relaciones) que le son propias, y la postulación de que la verdadera doctrina política y religiosa -la propia de la gran Civilización Cristiana- es aquella que admite el progreso y la libertad dentro del respeto debido a las tradiciones y a la conservación del orden social. ${ }^{56}$

Podemos concluir provisionalmente los muy rápidos trazos que hemos elaborado en las páginas de este artículo reproduciendo aquí una franca observación como casi todas las suyas- que hace Caro, sobre el tema que nos ocupó. "Si en vez de esta noble lengua neolatina -leía ante un auditorio de académicos de la lengua en la Bogotá de principios de los años 80-, hablásemos la lengua mosca, o cualquiera otra de las innumerables que pululaban en América antes de la conquista, vivas aun algunas de ellas, alumnas todas del uso y no adornadas de gloria literaria, ¿podríamos orar y escribir, versificar, filosofar, discutir, como ahora a nuestro sabor y a nuestras anchas; y con pensamientos tan oscuramente concebidos cuanto confusamente expresados nos sería permitido, ni por asomos, ni en la esperanza, tomar parte en el concierto de la civilización moderna?", 57 inquiría retóricamente nuestro autor.

La estrategia discursiva de integrar en la misma dinámica constituyente de la Civilización a la Lengua y al Ordenamiento social (como Autoridad), rinde jugosos frutos conceptuales. Al hacer posible la postulación de una correspondencia sustantiva entre una "gramática de la lengua" y una "gramática de la sociedad", entendiendo por "sociedad", la forma civilizada de sociedad, y partiendo de la elaboración de postulados histórico sociales entresacados de las ciencias del lenguaje de la época, por los que se establecen, entre otras cosas, diferencias sustantivas entre lenguas complejamente desarrolladas y lenguas de menor complejidad gramatical y léxica, Caro extrapola un modelo de jerarquización de las sociedades humanas y de los hombres que las constituyen, que naturaliza, retorizándolas, las gradaciones, contraposiciones, junturas y distanciamientos propios de la vida social. Teniendo en cuenta que para Caro el lenguaje es el primero y necesario elemento de sociabilidad, éste se autoconstituye en el mismo juego de vectores que se

${ }^{56}$ OB3-amer, p. 122.

${ }^{57}$ OB3-uso, pp. 60-66 
58 Deas, Malcom, Del Poder y la Gramática, 1993, Tercer Mundo Editores, Bogotá, $1^{\text {a }}$ Edición, p. 28.

${ }^{59}$ OB3-uso, p. 66 entrecruzan y combinan, avanzan y retroceden configurando la sociedadcivilización en la que el lenguaje se despliega y encarna, en un compartido camino que integra tradición y progreso, superioridad e inferioridad, hegemonía y subordinación.

Con Deas ${ }^{58}$ consideramos que la competencia filológica, pública y privada, entre sabios retóricos en la Colombia de la segunda parte del Siglo XIX estuvo íntimamente conectada con el ejercicio del poder. Como el lo afirma, el dominio de la lengua y sus leyes fue un componente muy importante en la hegemonía conservadora entre nosotros entre 1885 y 1930. Y si bien estas preocupaciones no tuvieron esencialmente motivación ni objetivos nacionalistas sino, incluso, antinacionalistas, en tanto internacionalistas o aún transnacionales -así podrían calificarse las preocupaciones por el cultivo y defensa de la "cultura latina" iberoamericana-, en todos los casos ellas sí fueron tributarias de una estrategia no propiamente democratizante de vernacularización de la hegemonía por parte de los sectores tradicionalmente elitarios de la sociedad a través del manejo magisterial de la lengua y sus saberes por parte de los lexicógrafos estadistas, de los gramáticos gobernantes, de los filólogos funcionarios, de los caudillos letrados, de prelados hermeneutas que coprotagonizaron la historia colombiana por esa época. En la Colombia que cumplía su modernización conservadurizadora en el tránsito del XIX al XX, la ciencia y la práctica de la hegemonía política se estructuraron y expresaron epistemológica, argumentativa y estilísticamente con las categorías, el lenguaje y los gestos de una hegemonía retórica.

Teniendo en consideración lo anterior, podemos prever el alto grado de asentimiento del conciliábulo de académicos ante quien Caro, acto seguido, se responde, elocuentemente persuadido: “iNo, señores! Participación tan gloriosa, sólo se nos concede a condición de usar de una lengua clásica, la castellana... no la lengua del vulgo, del trato común y de comercio, sino la propia de los escritores clásicos de la nación española". ${ }^{59}$ Dixit.

\section{BIBLIOGRAFIA}

\section{Obras de Miguel Antonio Caro}

Caro, Miguel Antonio, Obras, Tomo I, Filosofía, Religión, Pedagogía, Clásicos Colombianos, Instituto Caro y Cuervo, Bogotá, 1962

CODIGO: OB1 


\begin{tabular}{|l|l|l|c|}
\hline ARTICULO, CONFERENCIA O LIBRO & FUENTE ORIGINAL & FECHA & CODIGO \\
\hline El Darwinismo y las Misiones & El Repertorio & $\begin{array}{l}\text { (09) } 1886 \\
\text { Colombiano }\end{array}$ & $\begin{array}{l}\text { OB1-darw } \\
\text { (02) 1887 }\end{array}$ \\
& & & \\
\hline
\end{tabular}

Caro, Miguel Antonio, Obras, Tomo II, Gramática de la lengua latina para el uso de los que hablan castellano, Instituto Caro y Cuervo, Clásicos Colombianos, VI, Bogotá, 1972. CODIGO: OB2

\begin{tabular}{|l|l|l|l|}
\hline ARTICULO, CONFERENCIA O LIBRO & FUENTE ORIGINAL & FECHA & CODIGO \\
\hline Gramática de la lengua latina & $\begin{array}{l}\text { Introducción a } \\
\text { la } 4^{\text {a Edición }} \\
\text { para el uso de los que hablan } \\
\text { castellano }\end{array}$ & (09) 1886 & OB2-int \\
\hline
\end{tabular}

Caro, Miguel Antonio, Obras, Tomo III, Estudios Lingüísticos, gramaticales y filológicos, Clásicos Colombianos VIII, Bogotá, 1980. CODIGO: OB3

\begin{tabular}{|c|c|c|c|}
\hline ARTICULO, CONFERENCIA O LIBRO & FUENTE ORIGINAL & FECHA & CODIGO \\
\hline $\begin{array}{l}\text { Americanismo en el lenguaje } \\
\text { (Discurso; Academia Mercantil } \\
\text { de Simón O'Leary, Bogotá) } \\
\end{array}$ & $\begin{array}{l}\text { El Repertorio } \\
\text { Colombiano }\end{array}$ & (07) 1878 & OB3-amer \\
\hline $\begin{array}{l}\text { ARTICULO, CONFERENCIA O LIBRO } \\
\text { Diccionarios Castellanos }\end{array}$ & \begin{tabular}{|l} 
FUENTE ORIGINAL \\
Revista de Bogotá \\
(reseña al Diccionario \\
delaLengua Castellana \\
de la Academia \\
Española de 1869)
\end{tabular} & $\begin{array}{c}\text { FECHA } \\
(08) 1871\end{array}$ & $\begin{array}{r}\text { CODIGO } \\
\text { OB3-dic }\end{array}$ \\
\hline $\begin{array}{l}\text { Manual de Elocución, } \\
\text { o Principios del arte de } \\
\text { leer y recitar }\end{array}$ & $\begin{array}{l}\text { Fonética y Ortografía, } \\
\text { en Del uso en sus } \\
\text { relaciones con el } \\
\text { lenguaje }\end{array}$ & $(01) 1881$ & OB3-eloc \\
\hline $\begin{array}{l}\text { Del uso en sus relaciones } \\
\text { con el lenguaje }\end{array}$ & \begin{tabular}{|l} 
El Repertorio \\
Colombiano \\
(Versión de conferencia \\
ante Academia \\
Colombiana de la \\
Lengua, Bogotá)
\end{tabular} & $(01) 1881$ & OB3-uso \\
\hline $\begin{array}{l}\text { Gramática... parda. } \\
\text { Página para colegiales }\end{array}$ & La Nación & (03) 1888 & OB3-par \\
\hline $\begin{array}{l}\text { Sobre el Castellano } \\
\text { en América) }\end{array}$ & $\begin{array}{l}\text { Trascripción } \\
\text { de conferencia } \\
\text { ante Academia } \\
\text { Mercantil de Simón } \\
\text { O'Leary, Bogotá }\end{array}$ & (03) 1878 & OB3- conf \\
\hline $\begin{array}{l}\text { Contradiálogo } \\
\text { de las Letras }\end{array}$ & $\begin{array}{l}\text { El Repertorio } \\
\text { Colombiano }\end{array}$ & 1880 & OB3-cont \\
\hline
\end{tabular}


Otros Autores

Curcio Altamar, Antonio, Ideario Hispánico, Instituto Colombiano de Cultura Hispánica, Bogotá, 1952.

Deas, Malcom, Del Poder y la Gramática, 1993, Tercer Mundo Editores, Bogotá, $1^{\text {a }}$ Edición

Guerrero, Gerardo, “Universidad Pública: Modernización y Modernidad 1826-18880, en Revista Historia de la Educación Colombiana, Universidad Pedagógica y Tecnológica de Colombia, Año I, Nº 1, Octubre 1998, p. 109.

Torres Quintero, Rafael, Caro, defensor de la integridad del idioma, Estudio Preliminar, Tomo III de Obras, Colección Clásicos Colombianos VIII, Instituto Caro y Cuervo, Bogotá, 1980. CODIGO: DEF.

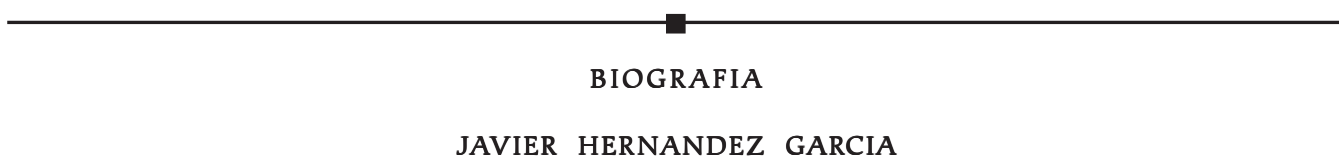

Filósofo Universidad de los Andes, Especialista en Teorías, Métodos y Técnicas de Investigación Social de la Universidad de Cartagena, Docente de la Facultad de Ciencias Sociales y Educación. 